\title{
La mediación comunitaria y/o vecinal: un aporte a la democratización social y un nuevo espacio para el trabajo social de comunidad*
}

\author{
Estela Adasme Calisto** \\ Christian Quinteros Flores ${ }^{* *}$
}

\begin{abstract}
RESUMEN
La técnica de la mediación se ha ampliado en Chile desde espacios tradicionales como el escolar o el familiar, a otros espacios menos habituales como el laboral e incluso el comunitario o vecinal. Sin embargo, en este último ámbito, su utilización en Chile hoy es muy incipiente y reviste desafíos a la institucionalidad y a quienes la operan en el marco de la nueva gestión pública. Para el Trabajo Social -importante operador de la política pública y responsable de contribuir a la necesaria "democratización social”-, este tipo de mediación puede constituir un buen recurso o bien público al momento de fortalecer el tejido social, además que le permite aprovechar la expertise de la formación recibida por este profesional. Este artículo busca contextualizar sociohistóricamente la práctica de la mediación comunitaria en Chile, permitiendo explorar algunas oportunidades que presenta hoy este espacio para el Trabajo Social, en épocas de globalización.
\end{abstract}

Palabras clave: Ciudadanía, Desarrollo Sinergético, Mediación VecinalComunitaria, Trabajo Social de Comunidad.

\section{A mediação comunitária e/ou da vizinhança: uma contribuição para a democratização social e um novo espaço para o trabalho social de comunidade}

A técnica de mediação tem se expandido no Chile desde espaços tradicionais, tais como a escola e a família, para outros espaços menos tradicionais, tais como o trabalho e até mesmo o comunitário ou vizinhança. No entanto, neste último aspecto, seu uso no Chile hoje é muito incipiente

Artículo recibido: 24/02/2014. Artículo aprobado: 04/06/2014. Versión final: 08/09/2014.

* Chilena. Trabajadora Social, Magíster en Pedagogía en Educación Social, Universidad Católica de Guayaquil. Perito Social Defensoría Penal Pública. Docente Universidad del Pacífico, Chile. Correo electrónico: eadasmec@upacifico.cl

*.. Chileno. Trabajador Social, Magíster en Ciencia Política Universidad de Chile, Diplomado en Gestión Pública y Desarrollo Territorial OEA-FLACSO, Secretario de Estudios Universidad del Pacífico, Chile. Correo electrónico: cquinteros@upacifico.cl 
e reveste de desafios à institucionalidade e aqueles que operam no âmbito da nova gestão pública. Para o Trabalho Social - importante operador da política pública e responsável de contribuir a necessária "democratização social" - este tipo de mediação pode se constituir num bom recurso ou Bem público ao momento de fortalecer o tecido social, além do mais, que lhe permite aproveitar os conhecimentos da formação recebida por este profissional. Este artigo visa contextualizar sociohistoricamente a prática da mediação comunitária no Chile, permitindo explorar algumas oportunidades que hoje apresenta este espaço para o trabalho Social em tempos de globalização.

Palavras-chave: Cidadania, Desenvolvimento sinergético, Mediação Vizinhança-Comunitária, Trabalho Social de Comunidade.

\section{Community and/or neighborhood mediation: A contribution to social democracy and a new space for community social work}

\section{ABSTRACT}

The technique of mediation has expanded in Chile from traditional areas such as school or family to other less traditional such as labor and even the community or neighborhood. However, the latter is very new in Chile today and imposes challenges to institutions and to those who operate it under the new public management. For the Social Work - major operator of public policy and responsible for contributing to the necessary "social democracy" - this type of mediation can be a good resource to strengthen the social fabric and leverage expertise of this professional training. This article is aimed to socio historically contextualize community mediation practice in Chile exploring some opportunities today for social work in globalization times.

Keywords: Citizenship, synergistic development, neighborhood-community mediation, community social work.

\section{Introducción}

"Si analizamos de cerca la trayectoria seguida por exitosos países en desarrollo, conoceremos nuevas opciones de políticas posibles para todos los países y regiones, $y$ aprenderemos sobre valores y visiones del mundo que podrían propiciar acciones futuras de cooperación para el desarrollo y respuestas constructivas ante los desafíos mundiales más graves. El objetivo, como siempre, es acelerar en la medida de lo posible el progreso a gran escala, el cual eleva el estándar y ofrece más oportunidades a las personas de todos los países y comunidades, en todas las dimensiones clave del desarrollo humano, desde salud, educación y subsistencia, hasta la libertad personal para controlar y mejorar nuestras propias vidas" (Informe de Desarrollo Humano, 2013:11). 
Según el último informe de Desarrollo Humano, el mundo ha experimentado durante las últimas décadas un progreso social creciente. El "ascenso de los países del sur" es inobjetable y exige ahora nuevos desafíos, entre ellos, mayor justicia social, mayor libertad de las personas y ciudadanos y un Estado desarrollista. La mediación comunitaria y/o vecinal aparece en este sentido como una oportunidad de ampliar la libertad de las personas para controlar y mejorar sus propias vidas, exigiendo mejores conductas para la convivencia social y estableciendo un marco regulador donde el ciudadano participe directamente en la resolución de sus asuntos públicos sin necesidad en algunos casos de "judicializar" los conflictos o diferencias con otros (institucionalidad tradicional).

\section{La mediación social como técnica para promover construcción de ciudadanía}

Dentro de la llamada técnica de la mediación social -que bien puede considerarse un bien público- existen varios campos de acción, que más allá de sus especificidades y habilidades particulares, comparten lo central de toda mediación: la neutralidad, la equidad y la imparcialidad. En el área comunitaria se han desarrollado dos alternativas: mediar entre vecinos o mediar entre los distintos actores que intervienen en el espacio comunitario, ya sea vecinos, empresarios o autoridades. La mediación comunitaria representa para el Trabajo Social una interesante plataforma o espacio para modificar la realidad y lograr el anhelado equilibrio del binomio recurso - necesidad. Esta nueva área de intervención reviste potencialmente un gran aporte al desarrollo de una cultura democrática y pacífica. Actualmente, el Estado chileno está contribuyendo a esta cultura a través de la creación de las denominadas Unidades de Justicia Vecinal bajo la modalidad de proyectos pilotos (los cuales han aumentado su "fuerza" en los últimos años). También han incursionado en esta nueva modalidad de justicia cercana y local los municipios, en alianzas con corporaciones o fundaciones, o con financiamiento del Fondo Nacional de Seguridad Pública del Ministerio del Interior. Así, la mediación comunitaria ha tenido diversas aplicaciones, ya sea entre los propios vecinos (capacitados para la gestión en mediación) o entre los vecinos y la comunidad, a través de la existencia de un centro especializado propiciado por el municipio o 
el Estado a través del Ministerio del Interior. Resulta interesante comprender que las distintas áreas de la mediación son absolutamente complementarias y subsidiarias, como ocurre entre la mediación escolar y la mediación comunitaria, pues todas ellas intentan en definitiva educar para la buena convivencia social. El Estado podría potenciar el espacio ciudadano fortaleciendo las habilidades mediadoras de sus vecinos y creando o facilitando la creación de centros comunitarios de mediación, con profesionales especializados. Los autores de este artículo están convencidos de la "autoridad" de lo comunitario y lo local como espacio decisional, donde los sujetos aprenden los hábitos sociales y culturales que después proyectarán a través de conductas en otros espacios sociales más amplios y complejos.

"Una sociedad integrada se sustenta en instituciones sociales eficaces que permiten a las personas tomar acciones colectivas y aumentar la confianza y la solidaridad entre grupos. Tales instituciones incluyen organizaciones no gubernamentales formales, asociaciones y cooperativas informales y normas y reglas de comportamiento. Influyen sobre los resultados individuales en desarrollo humano, al igual que sobre la cohesión y la estabilidad social" (Informe de Desarrollo Humano, 2013: 34). Ya en la Constitución chilena de 1822 se hablaba de los "Jueces de Paz", institución encargada de "componer a los litigantes" y, no pudiendo conseguirlo, debía procurar comprometerlos como "hombres buenos". Esta disposición luego desaparece en la Constitución de 1833, pero reviste gran importancia respecto a la aplicación de ley en el espacio vecinal en Chile, lo que indica que ha sido una preocupación histórica del Estado, quizás sin los resultados esperados. En 1971 se presentó un proyecto de Ley sobre Tribunales Vecinales, "el cual, consciente y preocupado del problema, estimó que era necesaria la creación de tribunales que sean más accesibles al poblador y al obrero, y que estén integrados por ellos mismos para así asegurarles que sus problemas van a ser bien interpretados" (Celedón, 2012: 50).

La mediación comunitaria actualmente consiste en una alternativa no jurídica y basada en el acuerdo entre vecinos, facilitados por un equipo profesional, que abre sin dudas enormes posibilidades de justicia cercana o al alcance de "todos". La mediación comunitaria aparece como un buen recurso para la inclusión so- 
cial de los grupos más desfavorecidos al acercarlos a una adecuada y razonable "sensación" de mayor justicia.

"A menos que las personas puedan participar de manera significativa en los eventos y procesos que dan forma a sus vidas, los caminos del desarrollo humano nacional no serán deseables ni sostenibles. Las personas deben poder influir en la formulación de políticas y resultados, y los jóvenes en particular deben ser capaces de aspirar a mayores oportunidades económicas y de responsabilidad y participación política" (Informe de Desarrollo Humano, 2013: 91). Siguiendo con esta línea de argumentación, esta alternativa de trabajo comunitario promueve y facilita la participación de la propia comunidad en su desarrollo, expandiendo sus capacidades locales, reconociendo sus valores culturales, filosofías y cosmovisiones de mundo que subyacen a las prácticas humanas que están presentes en la vida en comunidad, contribuyendo al fortalecimiento de su ciudadanía.

\section{Enfoques para comprender ciudadanía}

Como se señala en el cuadro $N^{\circ} 1$, no existe una única forma de comprender la ciudadanía de un sujeto. En este sentido, la ciudadanía republicana aparece como el marco más adecuado y pertinente para incluir la mediación comunitaria y/o vecinal: 


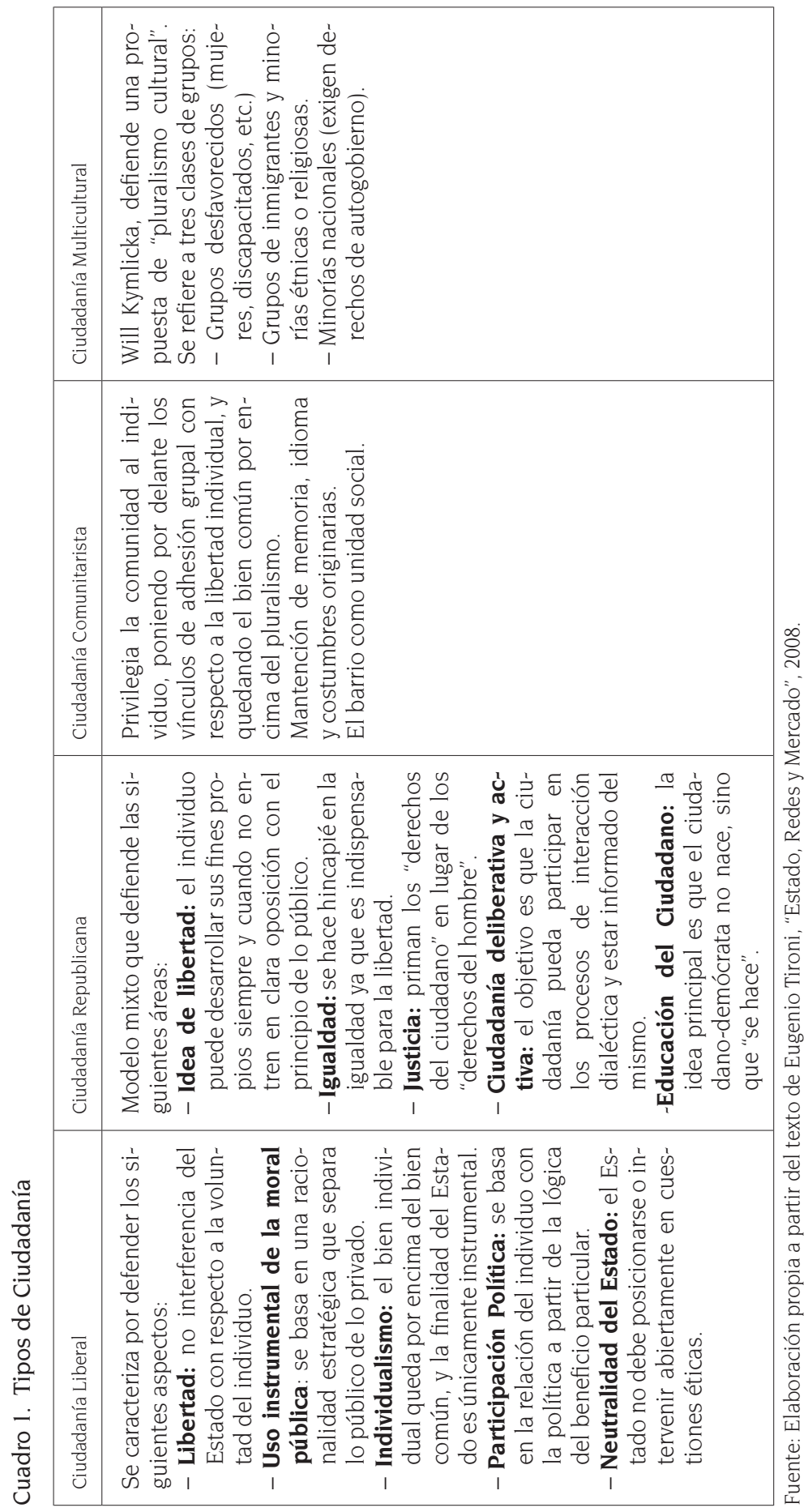


Por otra parte, desde la perspectiva de Habermas, la ciudadanía "contempla que los sujetos tienen más posibilidades de tornarse ciudadanos en la medida que se sienten autores de las leyes que los rigen" (Muñoz, en Celedón, 2012). Asimismo, la construcción de ciudadanía está asociada a un nuevo proceso llamado "individualización", que significa que cada persona debe definir por sí misma las elecciones, valores y relaciones que hacen su proyecto de vida; es un proceso mediante el cual las personas se distancian de las tradiciones heredadas y afirman el derecho a definir por su cuenta y riesgo lo que quieren ser. Esto es el resultado de la valoración social de la autonomía personal, de la pérdida de autoridad de las tradiciones y del aumento de alternativas en los modos de vida" (Informe de Desarrollo Humano, 2000: 28).

\section{La difícil tarea de definir Desarrollo}

Frente a la complejidad de definir y precisar "desarrollo", Calcagno y Calcagno establecen cinco dimensiones que incorpora este concepto: la paz como la base fundamental, la economía como motor del progreso, el medio ambiente como base de la sostenibilidad, la justicia como pilar de la sociedad y la democracia como buen gobierno (Calcagno y Calcagno, citado en Tironi, 2008). Según el PNUD, "El ascenso del Sur no es el resultado de adherir a un conjunto específico de recomendaciones políticas, sino de implementar políticas pragmáticas que responden a las circunstancias y oportunidades locales, como la profundización del papel fundamental de los Estados para alcanzar el desarrollo, la dedicación a mejorar el desarrollo humano (lo cual incluye apoyar la educación y el bienestar social) y una mayor apertura al comercio y la innovación. De todas maneras, el progreso futuro exigirá a los responsables de formular políticas prestar especial atención a aspectos como: igualdad, voz y rendición de cuentas, riesgos ambientales y cambios demográficos" (Informe de Desarrollo Humano, 2013: 1).

De acuerdo a este Informe, "Generalmente el crecimiento es mucho más efectivo en cuanto a reducción de la pobreza en países donde la desigualdad de ingresos es baja que en aquellos donde hay una desigualdad elevada. Promover la igualdad, especialmente entre diferentes grupos religiosos, étnicos o raciales, también contribuye a minimizar el conflicto social. Contar con educación, 
atención de la salud, protección social, empoderamiento legal y organización social permite que las personas pobres participen en el crecimiento. No obstante, incluso estos instrumentos de políticas básicas pueden no ser suficientes para empoderar a los grupos marginados (Informe de Desarrollo Humano, 2013: 5).

\section{El Territorio como una unidad compleja de Desarrollo}

El destacado planificador Sergio Boisier desarrolló el concepto de "Capital Territorial Sinergético", entendido como la "capacidad social o, mejor, a la capacidad societal (como expresión más totalizante) de promover acciones en conjunto dirigidas a fines colectiva y democráticamente aceptados, con el conocido resultado de obtenerse así un producto final que es mayor que la suma de los componentes" (Boisier, 1999: 5). En términos simples, significa que "El desarrollo bien entendido es un fenómeno de orden cualitativo en tanto que se le trata de alcanzar mediante acciones de orden cuantitativo" (Boisier, 1999: 6). Su propuesta también implica apoyarse del concepto de "Capital Sinergético" para fomentar y organizar nueve formas de capital, como económico, cognitivo, simbólico, cultural, institucional, psicosocial, social, cívico y humano, ya que éstas pareciese que están estrechamente más relacionadas con el desarrollo territorial que la misma construcción de infraestructura u otro tipo de acciones. 


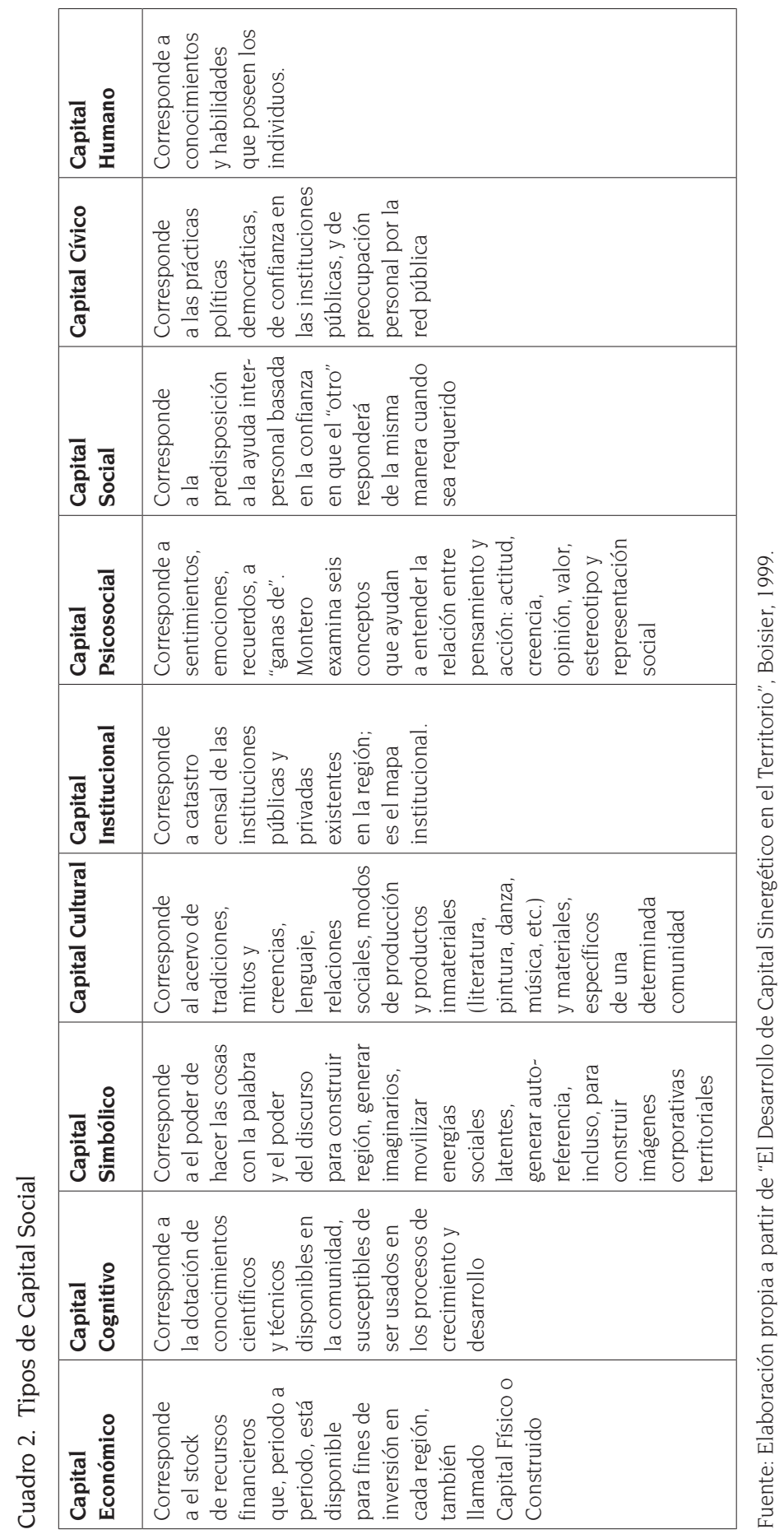




\section{Elementos comprensivos para abordar el concepto de Comunidad}

La comunidad ha sido el concepto central de la filosofía política y jurídica. Según Friedrich, desde sus orígenes ha sido considerada como un grupo humano con el cual se ha relacionado la política y el derecho, al cual hay que referir los fenómenos característicos de la vida política: la ley, el poder, la autoridad (Friedrich, 1969). Para Aristóteles, la comunidad está siempre “apuntando a algún bien”, ya que se trata de un grupo de hombres con algunos valores comunes (costumbre, creencia, intereses); la Polis ideal requiere demasiada unidad. La comunidad supone la existencia de seres por sí mismos, pero con ciertos factores en común que los unen. Por otra parte, para Cicerón la ley es el criterio decisivo de la comunidad (Comunidad legal): "No es pueblo cualquier colectividad de hombres reunidos de cualquier manera, sino una agrupación de muchos asociados por convenio sobre derecho y por la comunidad de intereses" (Schiavetti, 1980). Para Cicerón la comunidad posee una base legal y racional. Por otra parte, para Santo Tomás de Aquino la comunidad perfecta es la "Civitas", es decir, si un grupo de seres humanos procuran el bien común nace una comunidad, independiente de su magnitud. Sólo es derecho verdadero lo que se dirige hacia el "bien común" y la "sustancia" de la comunidad son las personas" (Schiavetti, 1980).

\section{La comunidad y su personalidad: elementos para el desarrollo de la identidad Local}

Gierke y Maitland aceptaron la personalidad "real" de la comunidad, es decir, la comunidad tenía una existencia personal aparte de la de los miembros que la integraban (sustancia propia en el concepto aristotélico). La personalidad estaba basada en la tradición (continuitas) y en los vínculos afectivos (colligatio). (Citado en Schiavetti, 1980). Desde una visión un poco más contemporánea, las comunidades son entidades humanas localizadas geográficamente y organizadas en función de ciertos móviles, donde existen aspectos ecológicos o territoriales relativos al asentamiento poblacional, al entorno físico y a la infraestructura, y aspectos funcionales relativos a la forma de resolver sus problemas y satisfacer sus necesidades colectivas. La comunidad está amal- 
gamada a partir de determinados nexos o elementos de unidad. Así, entonces, comunidad local es parte de la sociedad global con autonomía restringida. La comunidad posee en su interior fuerzas psicoafectivas que trascienden sus componentes materiales (Ander Egg, 2000).

\section{Una mirada a los actores del Desarrollo Territorial y Comunitario}

Sin dudas que para comprender el rol de la mediación comunitaria / vecinal en cualquier tipo de desarrollo es necesario identificar los actores involucrados en él. Actualmente, en Chile aparecen como protagonistas claves del desarrollo territorial el Estado, los municipios y crecientemente las organizaciones que integran la sociedad civil. El Estado es la Nación políticamente organizada que requiere tres requisitos para constituirse: Territorio, Constitución Política (Organización Jurídica) y personas, sumado a un aspecto estructural: a) Participación en tareas que aseguren el crecimiento de la sociedad (Organismos Públicos, Poderes Ejecutivo, legislativo y Judicial) y b) Estructura Jurídica y Política: Estado es el núcleo de la toma de decisiones globales que interesan a una sociedad. Dentro de la estructura del Estado y a nivel microterritorial aparecen las municipalidades que son "Corporaciones autónomas de derecho público, con personalidad jurídica y patrimonio propio, cuya finalidad es satisfacer las necesidades de la comunidad local y asegurar su participación en el progreso económico, social y cultural de las respectivas comunas" (Artículo $N^{\circ} 1$, Ley N¹8.695 Orgánica de Municipalidades).

Otro integrante importante en este desarrollo comunitario es la sociedad civil -tercer actor que interviene en el espacio territorial y que representa los intereses particulares y corporativos de los distintos grupos que constituyen sociedad-y que forma parte de los sistemas de participación ciudadana, a través de las Juntas de vecinos y otras organizaciones comunitarias. Estas asociaciones de interés público están reguladas por la Ley № 19.418, cuerpo legal que establece normas sobre juntas de vecinos y demás organizaciones comunitarias. Esta Ley regula conceptos tales como "Unidad Vecinal", "constitución" y "funcionamiento" de una Junta de Vecinos o de una organización funcional. Dentro de las funciones y atribuciones se consideran: representar a los vecinos ante 
cualquier autoridad, institución o personas; aportar elementos de juicio y proposiciones, gestionar soluciones para la junta de vecinos, ejecutar iniciativas, ejercer el derecho a plena información, proponer programas y promover la defensa de los derechos constitucionales de las personas, velar por la integración al desarrollo y el mejoramiento de las condiciones de vida, promover el progreso urbanístico y procurar la buena calidad de los servicios a la comunidad (Ley $N^{\circ} 19.418$ ).

\section{La sociedad civil como factor clave de la democratización social}

Según Carmona, los principales ejes de debate sobre la participación ciudadana se refieren a que este tipo de acción social se presenta como una temática relevante en la escena contemporánea. La necesidad de generar mayor sustento y legitimidad en los sistemas democráticos vigentes como la descarga hacia la sociedad civil de responsabilidades y poder de decisión en diferentes campos de intervención pública, determinan su mayor protagonismo actual. En primer lugar, la perspectiva más difundida sobre este tema relaciona la expansión de formas diversas de participación ciudadana en los asuntos públicos con los problemas de gobernabilidad derivados de la crisis de representatividad política y la deslegitimación del Estado como ámbito exclusivo de representación de los intereses generales. Esta postura pone el acento en los límites que presentan los mecanismos de democracia representativa para expresar los intereses y diferentes derechos de gran parte de la ciudadanía (Carmona, 2012). Desde esta mirada, la incorporación de actores de la sociedad en las decisiones públicas permitiría introducir de manera más genuina las perspectivas de los grupos sociales y legitimar las acciones de gobierno al no depender exclusivamente de los procesos electorales. Otro autor que plantea una estrategia del Estado nación para recuperar su soberanía perdida (o deslegitimada) es Manuel Castells, quien señala que el Estado nación actual debe establecer alianzas con organismos sub-nacionales para recuperar soberanía junto con descentralizarse y aumentar los niveles de participación ciudadana en los asuntos de éste (Castells, 1999).

Una segunda postura destaca la importancia de la participación ciudadana al señalar que "el fortalecimiento de la intervención de 
la sociedad en los procesos de políticas puede ayudar a mejorar el desempeño gubernamental. Los discursos predominantes en esta línea postulan que los principios que rigen al ámbito de la sociedad civil son la autonomía, la solidaridad y la libertad, en contraposición a la lógica centralizada y jerárquica del Estado, en relación con el funcionamiento del sistema político. Se desprende de este enfoque que la sociedad civil estaría desvinculada de los intereses ligados a la legitimación de relaciones de poder institucionalizadas, ya que en este ámbito primaría el principio de la autonomía en relación a las estructuras del Estado y del sistema político" (Carmona, 2012: 171-172).

Una tercera postura -y que se vincula directamente con la anterior- parte desde la crítica a los procesos de privatizaciones y reforma neoliberal que dieron lugar a la restricción de la intervención estatal en la vida social y al avance de los intereses privados sobre los mecanismos de acción pública. Frente a ello, se resalta la necesidad de "republificar" el Estado, es decir, ampliar la intervención pública sobre los mecanismos de construcción de la agenda gubernamental y sobre los procesos de formulación de políticas. La participación ciudadana, encauzada a partir de distintos dispositivos de articulación multiactoral (consejos consultivos, mesas de concertación, gestión tercerizada de servicios), se presenta como una herramienta apropiada para recuperar el control social sobre las problemáticas públicas, un objetivo que los mecanismos de la democracia representativa no han logrado asegurar por sí solos (Carmona, 2012). Bajo estos argumentos, la mediación comunitaria aparece como un interesante dispositivo institucional que puede permitir aumentar el control de los ciudadanos sobre el espacio que les pertenece, desarrollando de esta manera, sentido y significado local territorial, un "imaginario colectivo común", como diría Boisier.

\section{La mediación vecinal y comunitaria como mecanismo efectivo de resolución de conflictos}

Según Rodríguez Saif, "los conflictos vecinales se caracterizan por dos notas esenciales: la perdurabilidad temporal, ya que se proyectan en el tiempo tanto histórica como modernamente y 
por el casuismo que preside esta materia dada la multiplicidad de supuestos que pueden generar situación, detención o contraposición de intereses, enturbiando las relaciones de vecindad; si la convivencia constituye el presupuesto social de las relaciones determinadas por la vecindad, los derechos sobre los bienes inmuebles constituyen un presupuesto jurídico" (Rodríguez Saif, en Celedón, 2012:47),

A nivel microsocial se comprende que los conflictos son formas de interacción entre dos partes, ya sean personas, grupos o comunidades, que tienen su origen en una diferencia de intereses, valores u objetivos, en aspiraciones incompatibles o antagónicas, ya sea de un modo ocasional o permanente y que induce a las partes a confrontarse en el intento de lograr sus fines. El "conflicto comunitario vecinal” emerge en los ámbitos más próximos a la vida de las personas asociados a la convivencia o coexistencia en un espacio territorial significativo para alguno de ellos. Es generado entre personas que se afectan de forma interdependiente y desarrollan conductas en relación a la circunstancia, ocurrencia, prolongación en el tiempo y manifestaciones variables. Ambas partes en conflicto sienten frustración de sus necesidades y calidad de vida, experimentan algún grado de hostilidad que puede escalar hacia daños psicológicos, físicos o a la propiedad, de forma unilateral o recíproca.

Los conflictos comunitarios causan algún grado de tensión a nivel familiar y vecinal, tampoco son el resultado de un comportamiento objetivo, ya que además de los fines concretos que los adversarios persiguen, se encuentran sus interpretaciones o percepciones de lo que está en disputa (elemento subjetivo e intersubjetivo). Por lo tanto, el conflicto aparecerá, si las partes así lo deciden, con independencia de que existan o no bases objetivas para sustentarlo, lo que dificulta su resolución y la cooperación de los involucrados. Habermas (1999) divide a la sociedad en el sistema, que a partir de la razón instrumental organiza las leyes, reglamentos, instituciones (educación, salud, la política, la legislación y el aparato judicial), el mercado y la burocracia administrativa; y el mundo de la vida, como el lugar donde interactúan las personas (mundos: objetivo, subjetivo y social), el mundo de la vida cotidiana y los saberes colectivos que derivan en la socialización de los individuos. 
Bajo esta perspectiva, el barrio se concibe como una comunidad de intereses y un espacio de interacción comunicativa diferenciadora, con lo cual definen su pertenencia a un territorio reconocido, tanto por geografía como por las relaciones que se dan en su interior; esto acentúa los rasgos de la parte que es externa a ese ámbito, condición que se denota como causante del conflicto y se pone de manifiesto para reclamar ante empresas contaminantes o desarrollar estrategias para acceder a la ayuda estatal. En la situación en que no sea posible lograr la estabilidad de acuerdos alcanzados con base en el diálogo, es común que se reclame a alguien que garantice el cumplimiento de un posible pacto, para que sea perdurable, y ante el temor de que la otra parte no lo respete. Un conflicto comunitario o vecinal requiere ser comprendido en una relación dinámica que rompe con los equilibrios estáticos con los que se lo suele analizar. En ocasiones, los involucrados del conflicto presentan una amplia trayectoria en que las posiciones entre afectado y quien afecta al otro se relacionan dinámicamente, siendo en algunos momentos uno el afectado y, en otros, el mismo es quien afecta al otro. Así, la mediación vecinal, desde una lógica sistémica, podría constituirse en una herramienta de estabilidad de una comunidad a partir de sus prácticas auto regulatorias que le ayudan a mantener el equilibrio y reducir la conflictividad (dispersión de componentes del sistema). En este contexto, el lenguaje y la comunicación cobran especial relevancia; desde la propuesta fenomenológica de Husserl o Habermas, son un medio para validar al otro, para reconocer su existencia; desde el aporte de Maturana, reconocer al otro como un "legítimo otro" disminuye las posibilidades de violencia.

\section{Diagnóstico y proyecciones de la mediación comunitaria y/o vecinal en Chile}

Durante este año 2014, se generarán en nuestro país fondos concursables desde el Ministerio del Interior, específicamente desde el área de seguridad ciudadana, que considerarán la creación de las unidades de justicia vecinal, una nueva política pública justamente para crear centros de mediación comunitaria, dados los buenos resultados de las experiencias pilotos realizadas durante 2012 y 2013. Por otra parte, el Fondo Nacional de Seguridad Pública del Ministerio del Interior establecerá financiamiento para estudios e implementación de centros de mediación comunitaria. 
La instalación de centros de mediación comunitaria se realizan en el marco de proyectos de colaboración entre las municipalidades y el Ministerio del Interior en el contexto de la seguridad pública, y donde los profesionales integrantes resultan provenir de distintos campos disciplinarios, tales como el derecho, la sociología, y el trabajo social, entre otros. Creemos que es imprescindible levantar diagnósticos comunitarios que identifiquen eventuales y potenciales focos de conflicto intravecinal como comunitarios, con sus orígenes históricos, tradiciones o factores psicosociales, dado que la comprensión del conflicto debe siempre estar focalizada en las características locales para comprender las diferentes realidades comunitarias.

Por otra parte, hoy no existe un procedimiento estandarizado para constituir un centro de mediación comunitaria. Las experiencias conocidas por los autores se desprenden desde las funciones no privativas de los municipios. Por ejemplo, los municipios de Peñalolén y Lo Espejo han postulado a fondos concursables en el marco de las directrices de la seguridad ciudadana como estrategia de prevención; sin ir más lejos, durante el 2015 se generarán otros fondos de concursos para crear centros de mediación comunitaria. Es así como las experiencias chilenas en materia de mediación comunitaria o vecinal han estado mayormente vinculadas con las municipalidades, ya que éstas pueden generar alianzas con otros organismos para abordar diferentes temáticas, y una de ellas está relacionada con la seguridad ciudadana. Dentro del Ministerio del Interior también existen fondos concursables dentro de los cuales se han presentado proyectos de mediación comunitaria como estrategias de prevención y tratamiento de la seguridad comunal.

Hoy, tampoco se aprecia un camino formal para presentar proyectos a los municipios; esto depende en gran medida de la capacidad emprendedora de eventuales interesados en generar una oficina de mediación comunitaria y de la voluntad política de la autoridad comunal. En este sentido las municipalidades, de acuerdo a la Ley 18.695, tienen las Unidades de Desarrollo Comunitario, cuya obligación es asesorar a las organizaciones comunitarias sobre su funcionamiento y regulación; desde esta función se podría proponer alguna orientación técnica ante un eventual conflicto. Sin duda, las municipalidades tienen los departamentos de Organizaciones comunitarias que administran la 
aplicación de los alcances de la Ley 19.418. Otras opciones que ofrece la actual institucionalidad la constituyen las unidades de mediación de las CAJ (Corporaciones de Asistencia Judicial) o las UJV (Unidades de Justicia Vecinal).

Así, creemos que la mediación comunitaria, ya sea a nivel vecinal o a través de un centro de mediación formal (municipal o UJV), constituye un excelente espacio para fortalecer la ciudadanía (tejido social) y generar un modelo de desarrollo potenciando principios democráticos y participativos a nivel local. En segundo lugar, sería pertinente y relevante potenciar la capacidad de diagnóstico de la comunidad desde la aplicación de supuestos teóricos y epistemológicos que faciliten la identificación y comprensión de las lógicas comunicativas y humanas subyacentes a cada una de las realidades comunitarias. Al mismo tiempo, se debe valorar la elaboración de proyectos como una adecuada herramienta para "comunicar" propuestas y racionalizar las decisiones entre los actores comunitarios, autoridades, organizaciones y la propia comunidad. Los fines de la mediación comunitaria -la solidaridad, la justicia cercana, la cultura de paz- sintonizan plenamente con los principios del Trabajo Social y, por lo tanto, pueden constituirse en áreas absolutamente complementarias y recíprocas.

\section{Comentarios finales}

A la luz de lo revisado en este artículo, el contexto histórico de la mediación comunitaria en Chile (pasado y presente) y los nuevos escenarios sociales, hacen favorable la consolidación de un sistema de justicia vecinal que incorpore progresivamente esta metodología. El enfoque de desarrollo humano predominante en las políticas públicas y el desarrollo tecnológico de la profesión del Trabajo Social propiciarían instalar este tipo de modelo de gestión en nuestras comunidades para potenciar su protagonismo, para que democráticamente y responsablemente intervengan en sus conflictos y acuerdos.

La mediación comunitaria y/ o vecinal representa, en cualquiera de sus dos formas, un conjunto de beneficios sociales y de aportes a la democratización social del territorio, fortaleciendo su capital social, psicosocial y simbólico en el concepto de Boisier. Este tipo de mediación tiene la oportunidad de aportar en generar una cultura de responsabilización y aprendizaje de resolución 
de conflictos a nivel comunitario, aumentando la eficiencia del proceso de desarrollo local. La responsabilidad en el conflicto, no solo individual sino también de actores u organizaciones dentro de la comunidad, fortalece una cultura comunicativa y de diálogo a nivel comunitario y disminuye la vulnerabilidad social de las personas, ya que se vincula con su posibilidad de asociatividad y fortalecimiento de la sociedad civil. Desde el constructivismo -enfoque epistemológico que propone construir la realidad a partir del lenguaje y los códigos-, la mediación comunitaria permite a los sujetos o vecinos dialogar, situarse en igualdad de condiciones frente a un conflicto, generando una nueva oportunidad para potenciar vínculos en la comunidad. En este sentido, los trabajadores sociales poseen los recursos técnicos para generar, procesar y concluir información que permita actuar proactivamente frente al conflicto de la comunidad.

La aplicación de la técnica de la mediación fortalece, sin duda, el sentido de comunidad desde la visión aristotélica (bien común, amistad, virtudes), desarrolla capital sinergético y les entrega a los propios vecinos la posibilidad de mediar entre sí en un primer nivel o de requerir apoyo más especializado como el que podría generarse con la creación de un centro municipal de mediación comunitaria/vecinal. Consideramos que nuestra profesión es una alternativa totalmente vinculada con los principios, modelos y técnicas de mediación, sumado a las habilidades, competencias y destrezas necesarias para desarrollar esta metodología de intervención, intentando aportar a una cultura de acuerdos. Si bien reconocemos que no es un espacio privativo del campo del Trabajo Social -y por lo tanto queda fuera del monopolio de sus actividades-, es un buen espacio para fortalecer la participación de los ciudadanos en sus propios asuntos, buscando aportar solidariamente a una cultura de paz.

\section{Bibliografía}

Ander Egg, E. (2000). Metodología y Práctica del Desarrollo de la Comunidad. Argentina: Editorial Lumen

BCN (2014). Ley $N^{\circ} 18.695$ Orgánica Constitucional de Municipalidades. Recuperado de www.bcn.cl

BCN (2014). Ley N 19.418 Orgánica Constitucional sobre Juntas de Vecinos y Otras organizaciones comunitarias. Recuperado de www.bcn.cl 
Boisier, S. (1999). El Desarrollo Territorial a partir de la Construcción de Capital Sinergético. Estudios Sociales $N^{\circ} 99$, Santiago de Chile: C.P.U.

Castells, M. (1999). Globalización, Identidad y Estado en América Latina. Temas de Desarrollo Humano Sustentable, Santiago de Chile: PNUD - Ministerio Secretaría general de la Presidencia.

Carmona, R. (2012). Políticas públicas y participación ciudadana en la esfera local. Análisis y reflexiones a la luz de la experiencia argentina reciente. Revista Chilena de Administración Pública, Nº19, pp. 169-185. Santiago de Chile: Universidad de Chile.

Celedón, A. (2012). Justicia vecinal: un desafío para Chile. En Israel, R.; Villagrán, M. (2012). Reflexiones sobre la Sociedad Chilena: Una Mirada desde la Universidad. Santiago de Chile: RIL Editores.

Friedrich, C. (1969). El concepto de comunidad en la historia de la filosofía política y jurídica. En La Comunidad y el Derecho, pp. 15-33. México: Editorial Roble.

PNUD (2002). Desarrollo Humano en Chile. Nosotros los chilenos: un desafío cultural. Informe de Desarrollo Humano. Santiago de Chile: PNUD.

PNUD (2013). El ascenso del Sur: progreso humano en un mundo diverso. Informe de Desarrollo Humano. Santiago de Chile: PNUD.

Schiavetti, M. (1980). Amistad y Comunidad Política según Aristóteles. Revista de Ciencias Sociales $N^{\circ} 17$, pp.15-24. Valparaíso, Chile. EDEVAL.

Tironi, E. (2008). Redes, Estado y Mercado, Soportes de la Cohesión Social latinoamericana. Santiago de Chile: Editorial Uqbar. 
